\title{
ANALISIS SPESIFIK KONSUMSI BAHAN BAKAR PADA PEMBANGKIT LISTRIK TENAGA UAP DI NII TANASA DENGAN MENGGUNAKAN BAHAN BAKAR RENDAH KALORI
}

\author{
La Hasanudin ${ }^{1}$, Al Ichlas Imran ${ }^{2}$,Yuspian Gunawan ${ }^{3}$, Ridway Balaka $^{4}$, Budiman Sudia ${ }^{5}$, \\ Agustinus Lolok ${ }^{6}$, Aminur $^{7}$, Salimin $^{8}$, Samhudin $^{9}$, PrinobAksar $^{10}$ \\ 1,2,3,4,5,7,8,9 Teknik Mesin Universitas Halu Oleo \\ ${ }^{6}$ Teknik Elektro Universitas Halu Oleo \\ ${ }^{10}$ Teknik Mesin Sekolah Tinggi Mekongga Kolaka \\ ${ }^{1}$ La.hasanudin@uho.ac.id \\ 6Agustinus.gio@yahoo.co.id
}

\begin{abstract}
ABSTRAK
Konsumsi bahan bakar spesifik (SFC) dalam pembangkit listrik tenaga uap sangat penting untuk diketahui karena terkait dengan perbandingan total konsumsi bahan bakar, dimana Pembangkit Listrik Tenaga Uap Nii Tanasa menggunakan bahan bakar batubara terhadap tenaga listrik yang dihasilkan oleh generator listrik. Hal ini dilakukan untuk mengetahui seberapa efisien pembangkit listrik di industri di pembangkit listrik tenaga uap di Nii Tanasa dan juga untuk kemungkinan nilai kalor bahan bakar yang akan digunakan untuk pembakaran. Tujuan dari penelitian ini adalah untuk menganalisis Konsumsi Bahan Bakar Spesifik yang dibutuhkan dalam pembangkit listrik tenaga uap. Metode yang digunakan adalah metode langsung, input yang diperlukan adalah Gross $\mathrm{kWh}$, Net $\mathrm{kWh}$, penggunaan bahan bakar batubara. Jenis bahan bakar yang digunakan adalah lignit rendah kalori. Hasil Konsumsi Bruto pada bulan Januari terlihat 1,08 kg / kWh sedangkan Konsumsi Bahan Bakar Bersih adalah 1,25 kg/ kWh. Pada bulan Desember nilai Konsumsi Bahan Bakar Spesifik Bruto adalah 1,04kg / kWh sedangkan jumlah Konsumsi Bahan Bakar Spesifik adalah $1,17 \mathrm{~kg} / \mathrm{kWh}$. Nilainya relatif tinggi pada kapasitas $\leq 100 \mathrm{MW}$.
\end{abstract}

Kata Kunci: Specific fuel consumption, Tenaga Uap, batu bara, Listrik, Pembakaran

\section{ABSTRACT}

Specific Fuel Consumption Analysis Of Steam Power Plant In Nii Tanasa Using Low Fuel Calorie. Specific fuel consumption (SFC) in a steam power plant is very important to know because it is related to a comparison of the total consumption of fuel, where the NiiTanasa Steam Power Plant uses coal fuel against the electric power generated by an electric generator. This is done to find out how efficient a power plant in the generation industry is at the steam power plant in NiiTanasa and also for the probability of the heating value of the fuel to be used for combustion. The purpose of this study is to analyze the Specific Fuel Consumption needed in the power plant steam power. The method used is the direct method, the required input is Gross $\mathrm{kWh}$, Net $\mathrm{kWh}$, coal fuel use. The type of fuel used is low-calorie lignite. Gross Consumption Result in January looks $1.08 \mathrm{~kg} / \mathrm{kWh}$ while Net Specific Fuel Consumption is $1.25 \mathrm{~kg} / \mathrm{kWh}$. In December the value of Gross Specific Fuel Consumption was 1.04kg / kWh while the Specific Fuel Consumption Net amount was $1.17 \mathrm{~kg} / \mathrm{kWh}$. The value was relatively high at a capacity of $\leq 100 \mathrm{MW}$.

Key words: Specific fuel consumption, steam power, coal, electric, combustion

\section{PENDAHULUAN}

Konsumsi Bahan bakar pada umumnya merupakan bagian yang terpenting dalam operasi Pembangkit listrik tenaga Uap (PLTU) karena bahan bakar dapat berfungsi sebagai penyala awal dan juga pembakaran awal. Pada Sistem PLTU terdiri dari minyak HSD/High speed diesel(Solar) dan minyak MFO/Marine Fuel Oil(Residu). Bahan bakar sangat dipengaruhi oleh Konsumsi energy listrik yang besar kecilnya tergantung beban yang digunakan oleh 
pelanggang karena jumlah pasokan energi perlu dimanfaatkan secara optimal dan efisien.

Pembangkit listrik tenaga uap adalah solusi untuk memenuhi konsumsi energi, terutama di daerah pantai dimana air laut dapat dikonversi menjadi uap dan juga penggunaan batubara yang dikonversi secara termal menjadi uap. Dalam proses mengubah energi dari bahan kimia menjadi panas, diperlukan boiler, sementara perubahan energi dari mekanik ke listrik membutuhkan turbin dan energi dari mekanis ke perubahan listrik membutuhkan generator, yang kemudian didistribusikan ke konsumen [1].

Pada Penelitian yang dilakukan sebelumnya antara lain tentang efisien super kritikal batu bara, hubungan bahan bakar dan tingkat ekonomi, efesiensi thermal boiler dengan menggunakan batu bara, analisa Heat rate bahan bakar pada boiler, Efisiensi thermal pada system tenaga uap. Ada perbedaan signifikan antara peneliti sebelumnya dengan penulis, terutama menyangkut analisa spesifik konsumsi bahan bakar dengan menggunakan bahan bakar kalori rendah. [2], [3], [4], [5], [6]

Masalah yang selalu dihadapi oleh pembangkit listrik adalah bagaimana memprediksi nilai kalor dari bahan bakar yang digunakan untuk proses pembakaran. Lalu bagaimana perbandingan total rasio konsumsi bahan bakar dengan tenaga listrik yang dihasilkan. Jadi perlu dianalisis Konsumsi bahan bakar spesifik di pembangkit listrik tenaga uap. Kebaruan dari penelitian adalah Nilai Konsumsi Bahan Bakar Spesifik (Specific Fuel Consumption )yang berkaitan dengan efisien pembangkit listrik. Batubara dihancurkan dan dimasukkan ke boiler yang dibakar untuk memanaskan air menjadi uap. Uap disuntikan di bawah tekanan ke turbin yang mengubah generator. Uap yang kembali dari turbin kemudian didinginkan dalam kondensor, dan air diumpankan kembali oleh pompa air menuju boiler untuk melanjutkan proses sirkulasi [7], [8]. [9] [10].

Dalam boiler tabung air, aliran air serta uap di dalam tabung sedangkan gas panas mengalir ke permukaan luar. Sistem sirkulasi ketel dibangun dari tabung, header, dan drum yang disatukan dalam pengaturan yang menyediakan aliran air untuk menghasilkan uap sambil mendinginkan semua bagian. Konstruksi tabung air memungkinkan kapasitas boiler lebih besar dan tekanan lebih tinggi daripada desain shell atau tabung api Generator dengan pendingin udara pada sirkuit terbuka paling baik yang berkaitan dengan biaya dan persyaratan pendinginan, tetapi masalah dapat timbul sehubungan dengan kotoran/debu dan juga kebisingan. Generator yang didinginkan dengan hidrogen, pada kenyataannya, mencapai efisiensi yang lebih tinggi (terutama pada beban sebagian) daripada mesin berpendingin udara. Namun, tentunya membutuhkan alat bantu tambahan dan tentunya hasilnya, lebih mendistribusikan generator harmonik, seperti sistem penggerak frekuensi variabel, untuk mengurangi distorsi harmonik pada satu bus [11], [12], [13].

Penelitian ini bertujuan untuk menentukan konsumsi bahan bakar spesifik (Specific Fuel Consumption) dari pembangkit listrik tenaga uap di NiiTanasa Konawe, Sulawesi Tenggara. Konsumsi bahan bakar spesifik menarik untuk dikaji karena menyangkut kelayakan kelestarian generator yang harus dijaga, ini bisa dilihat berapa jumlah bahan bakar yang digunakan, lalu berapa banyak listrik yang dihasilkan baik kotor maupun bersih. Berdasarkan hal ini, penulis tertarik untuk meneliti lebih lanjut terutama pembangkit listrik tenaga uap yang menggunakan bahan bakar batubara kalori rendah.

\section{METODE PENELITIAN}

Metode yang digunakan dalam penelitian ini adalah menggunakan metode direct, yang merupakan bahan bakar yang digunakan dalam generator, akan dibandingkan secara langsung dengan energi output yang dihasilkan oleh generator. Dimana data yang digunakan bersumber dari data sekunder Pembangkit listrik tenaga uap di NiiTanasa dengan kapasitas 2 X 10 MW. Penelitian ini dilakukan pada bulan Juni- Agustus 2019, bertempat di PLTU Nii Tanasa Kabupaten Konawe dan Fakultas Teknik Universitas Halu Oleo.

Tahapan-tahapan penelitian sebagai berikut:

a) Dimasukan prosedur administrasi di PT. PLN (Persero) Cabang Kendari

b) Dilakukan observasi lapangan pendahuluan

c) Dikumpulkan data sekunder yaitu berupa data bahan bakar, data $\mathrm{kWh}$, data Konsumsi bahan bakar 2 semester, Jumlah Konsumen, besaran beban listrik yang digunakan 
d) Selanjutnya danalisia data-data tersebut dengan metode direct analysis. Konsumsi bahan bakar spesifik (SFC) adalah perbandingan dari total konsumsi bahan bakar, dimana di Nii Tanasa Steam Power Plant menggunakan bahan bakar batu bara untuk daya listrik yang dihasilkan oleh generator di industri pembangkit listrik. Hal ini dilakukan untuk mengetahui seberapa efisien pembangkit dalam industri pembangkitan di pembangkit listrik tenaga uap di Nii Tanasa dan juga untuk kemungkinan nilai kalor bahan bakar yang akan digunakan untuk pembakaran. Pembangkit Listrik yang beroperasi baik pada boiler rendah, memiliki $\mathrm{kWh}$ penggunaannya sendiri yang relatif rata-rata $147,94 \mathrm{kWh}$ untuk menjalankan peralatan pendukung seperti motor, pompa (pompa umpan Boiler) dan lainnya atau kebutuhan listrik seperti komputer dan lainnya [14], [15], [16].

Konsumsi bahan bakar spesifik (SFC) dapat menentukan kinerja mesin atau parameter kinerja yang terkait langsung dengan nilai ekonomi mesin. Berdasarkan parameter ini, jumlah bahan bakar batubara yang dibutuhkan di pembangkit listrik tenaga uap di Nii Tanasa untuk menghasilkan sejumlah daya tertentu dalam interval waktu tertentu. Perhitungan Konsumsi bahan bakar spesifik (SFC) menggunakan rumus berdasarkan SPLN nomor 80 pada tahun 1989 dengan persamaan 1 dan 2.

$$
\begin{array}{r}
S F C_{\text {Brutto }}=\frac{q_{f}}{k W h_{\text {Brutto }}} \ldots \ldots \ldots \ldots . . \\
S F C_{\text {Netto }}=\frac{q_{f}}{k W h_{\text {Netto }}} \ldots \ldots
\end{array}
$$

Dimana :

$S F C_{\text {Brutto }}=$ Spesifik Konsumsi bahan bakar Netto $\mathrm{kg} / \mathrm{kWh}$

$S F C_{\text {Brutto }}=$ Spesifik Konsumsi bahan bakar Brutto $\mathrm{kg} / \mathrm{kWh}$

$q_{f} \quad=$ Jumlah bahan bakar yang digunakan $(\mathrm{kg})$

$k W h_{N}=$ Data yang dihasilkan oleh generator setelah dikurangi oleh penggunaan generator sendiri (MW)

$k W h_{B} \quad=$ Data yang dihasilkan penting oleh generator (MW)

Prosedur kerja dalam penelitian ini dapat diilustrasikan melalui gambar 1 .

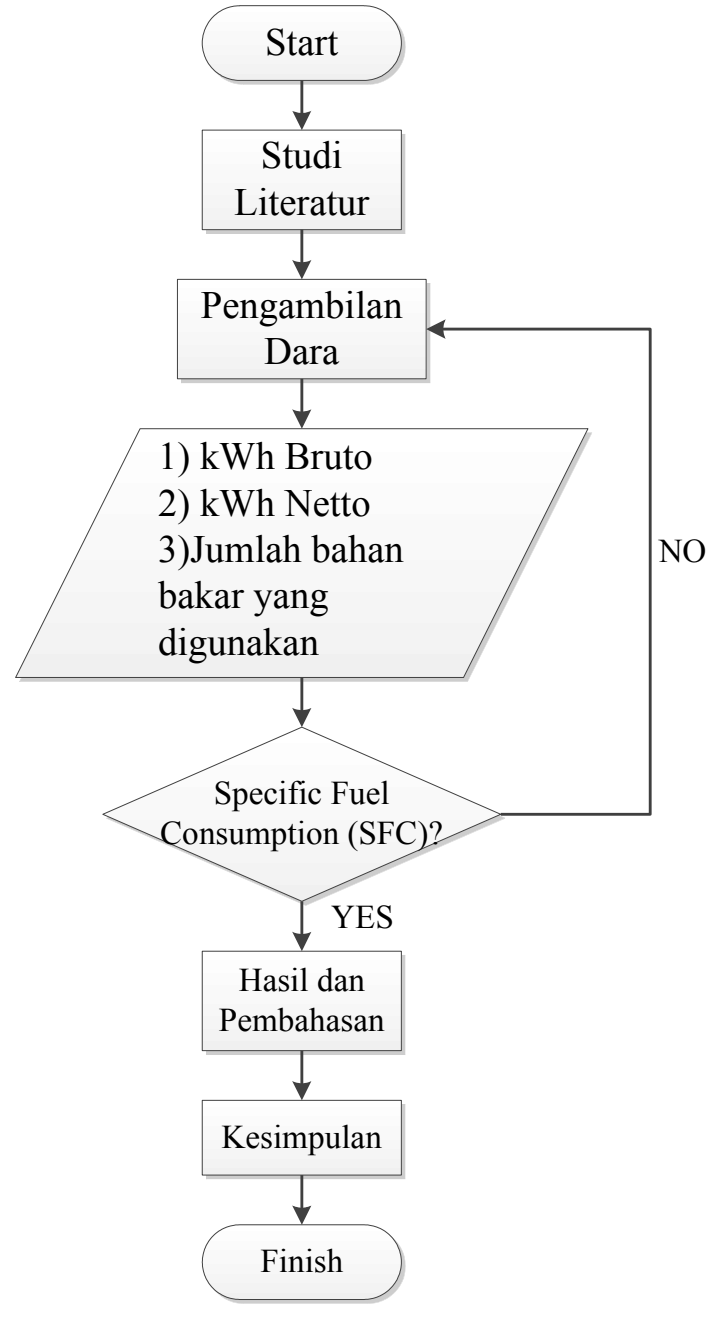

Gambar 1. Diagram alir penelitian

\section{HASIL DAN PEMBAHASAN}

Nilai konsumsi bahan bakar spesifik (SFC) di pembangkit listrik tenaga uap berdasarkan data semester satu dan semester dua yang diambil pada awal bulan dan akhir bulan.

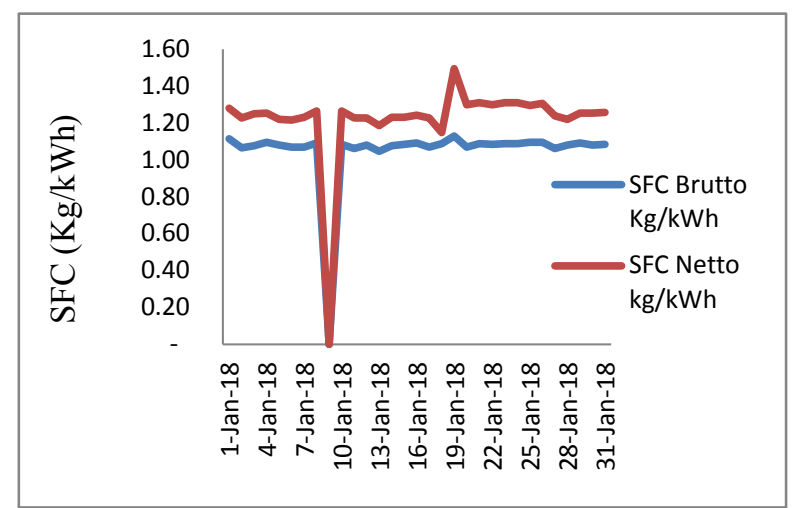

Gambar 2. SFC (kg / kWh) Nilai di Januari 2018 
Berdasarkan gambar 2 menunjukkan bahwa nilai Konsumsi Bahan Bakar Brutto (SFC) dapat dianalisis sebagai berikut : Ketika generator dibangkitkan menghasilkan nilai tertinggi pada 1 Januari sebesar $1,1 \mathrm{~kg} / \mathrm{kWh}$, sedangkan nilai terendah pada 9 Januari adalah 0 kcal / kWh. Nilai rata-rata sebesar1,08 kg / $\mathrm{kWh}$. Untuk 9 Januari, 0 $\mathrm{kg} / \mathrm{kWh}$ disebabkan karena tidak ada pengumpulan data pada hari itu. Pada data Nilai Konsumsi Spesifik bahan bakar Netto, dapat dianalisis ketika generator mendapat Load(beban), nilai tertinggi yang diperoleh pada 19 Januari adalah $1,50 \mathrm{~kg} /$ $\mathrm{kWh}$, sedangkan nilai terendah pada 9 Januari untuk $0 \mathrm{~kg} / \mathrm{kWh}$. Nilai rata-rata adalah 1,25 kg / kWh. Untuk 9 Januari, 0 kkal / kWh disebabkan karena tidak ada pengambilan data pada hari itu. Jika Anda melihat tren Polinominal cenderung meningkat sedikit tetapi tetap stabil, ini disebabkan oleh pengumpulan data pada bulan Januari untuk Gross kWh, Net kWh, Penggunaan Bahan Bakar, cenderung stabil. Hal ini sejalan dengan penelitian sebelumnya yang dilakukan oleh [4].

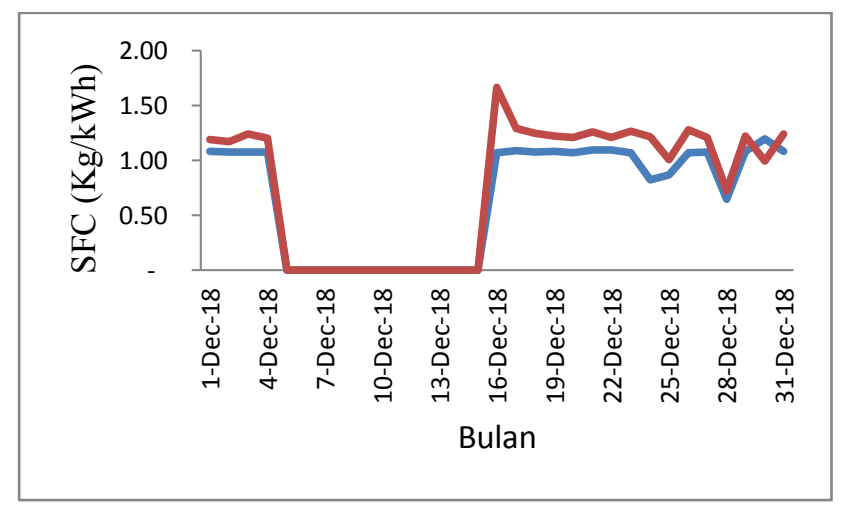

Gambar 3.SFC(kcal / kWh) Nilai di Desember 2018

Berdasarkan gambar 3 di atas menunjukkan nilai Konsumsi Bahan Bakar Brutto (SFC) dapat di analisis ketika generator dibangkitkanmenghasilkan nilai tertinggi pada 30 Desember pada $1,20 \mathrm{~kg} / \mathrm{kWh}$, sedangkan nilai terendah pada 5-15 Desember pada $0 \mathrm{kcal} / \mathrm{kWh}$. Nilai rata-rata adalah $1,04 \mathrm{~kg} / \mathrm{kWh}$. Untuk 5-15 Desember $0 \mathrm{~kg} / \mathrm{kWh}$ disebabkan karena tidak ada pengumpulan data pada hari itu. Pada data Nilai Konsumsi Spesifik bahan bakar Netto dalam analisis saat generator menghasilkan beban, diperoleh nilai tertinggi pada 16 Desember sebesar $1,67 \mathrm{~kg} / \mathrm{kWh}$, sedangkan nilai terendah pada 5-15 Desember dari $0 \mathrm{~kg} / \mathrm{kWh}$. Nilai rata-rata adalah 1,17 kg / kWh. Untuk 5-15 Desember 0 kcal / kWh disebabkan karena tidak ada pengumpulan data pada hari itu. Jika melihat tren Polinominal cenderung meningkat sedikit tetapi tetap stabil, ini disebabkan oleh pengumpulan data pada bulan Januari untuk Gross kWh, Net kWh, Penggunaan Bahan Bakar, cenderung stabil.Hal ini sejalan penelitian yang dilakukan oleh [2] dimana bahan bakar awal pada batu bara yang digunakan pada suatu boiler sebagai pembakaran awal harus cenderung stabil dalam penggunaanya.

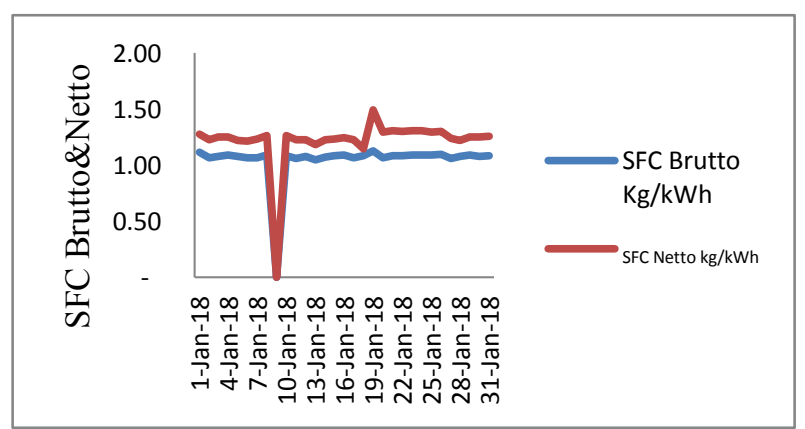

Gambar 4 Perbedaan nilai SFC Bruto dan SFC Netto

Berdasarkan gambar 4 menunjukkan perbedaan nilai Konsumsi bahan bakar spesifik (SFC) antara Buro dan Netto, di mana nilai bahan bakar Spesifik Netto (SFC) lebih tinggi dari nilai Konsumsi Bahan Bakar Bruto (SFC) . Hal ini terjadi karena jumlah pembagi SFC Net lebih kecil sehingga menghasilkan nilai yang lebih besar dan juga secara teknis penggunaan generator tetap dapat dipertahankan karena nilainya masih dalam kategori yang diizinkan untuk pengoperasian Generator. Penelitian ini sejalan yang dilakukan oleh [6] tentang analisa Heat rate yang dilakukan sebelumnya pada PLTU Ni Tanasa, dimana nilainya dalam kategori yang di izinkan.

Jika ada peningkatan beban atau daya yang dihasilkan oleh generator, konsumsi bahan bakar spesifik (SFC) berkurang. Ini berarti bahwa jumlah konsumsi bahan bakar spesifik (SFC) per kWh yang dikonsumsi oleh listrik cenderung lebih besar daripada beban Energi listrik.

\section{KESIMPULAN}

Adapun kesimpulan dari penelitian ini adalah nilai tertinggi konsumsi bahan bakar khusus (SFC) pada 1 Januari adalah $1,1 \mathrm{~kg} / \mathrm{kWh}$, sedangkan nilai terendah pada 9 Januari adalah $0 \mathrm{kcal} / \mathrm{kWh}$. Nilai rata-rata adalah $1,08 \mathrm{~kg} / \mathrm{kWh}$. Untuk tanggal 19 
januari diperoleh nilai tertinggi sebesar $1,50 \mathrm{~kg} /$ kWh, sedangkan nilai terendah pada 9 Januari adalah $0 \mathrm{~kg} / \mathrm{kWh}$. Untuk Konsumsi Bahan Bakar Brutto (SFC) nilai tertinggi dihasilkan pada 30 Desember pada $1,20 \mathrm{~kg} / \mathrm{kWh}$, sedangkan nilai terendah pada 5-15 Desember adalah $0 \mathrm{kkal} / \mathrm{kWh}$. Nilai rata-rata adalah 1,04 kg / kWh. Dalam data Konsumsi Bahan Bakar Netto (SFC), dapat dianalisis saat generator menghasilkan beban yang diperoleh nilai tertinggi pada 16 Desember adalah $1,67 \mathrm{~kg} / \mathrm{kWh}$, sedangkan nilai terendah pada 5-15 Desember adalah $0 \mathrm{~kg} / \mathrm{kWh}$. Nilai rata-rata adalah $1,17 \mathrm{~kg} / \mathrm{kWh}$. Nilai Konsumsi Bahan Bakar Spesifik Nilai Konsumsi Bahan Bakar Bruto pada dasarnya adalah untuk mengetahui seberapa efisien pembangkit listrik di industri pembangkit di pembangkit listrik tenaga uap di Nii Tanasa dan juga untuk kemungkinan nilai kalor dari bahan bakar yang akan digunakan untuk pembakaran. Berdasarkan hasil ini masih layak untuk melanjutkan operasional Pembangkit.

\section{DAFTAR PUSTAKA}

[1] A. rakhman, "https://rakhman.net/power-plantsid/sistem-bahan-bakar-minyak-pada-pltu/," july 2013. [Online]. Available:

https://rakhman.net/power-plants-id/sistem-bahanbakar-minyak-pada-pltu/.

[2] cahyadi, "(Pembangkit listrik batu bara super kritikal yang efesien)," B2TE BPPT, Tangerang Selatan, 2015.

[3] Z. arifin, "Konsumsi BBM untuk Pembangkit Listrik di Indonesia; Kecenderungan permasalahan dan solusinya," $M \& E$, vol. 13, no. 2, pp. 85-95, 2015.

[4] Adnal, "Analisis efisiensi thermal PLTU Nii Tanasa dengan memakai bahan bakar rendah kalori berkapasitas $2 * 10 \mathrm{MW}$," Skripsi Pendidikan Fisika FKIP UHO, Kendari, 2019.

[5] L. Hasanudin, "Heat Rate System Analysis In The Steam Power Plant In Niitanasa Using Environmentally Friendly Low-Calorie Fuels," in Conference Proceedings 5th ICSTR Bangkok-
International Conference on Science \& Technology Research, 23-24 December 2019, Bangkok, 2019.

[6] L. Hasanudin, " Thermal Efficiency Analysis On The Steam Power Plant In Nii Tanasa By Using A TwoSemester Direct Method With A Capacity Of $2 * 10$ Mw," Jurnal Fokus Elektroda : Energi Listrik, Telekomunikasi, Komputer, Elektronika dan Kendali, vol. 4, no. 3, pp. 1-6, 2019.

[7] R. L. Evans, "Fueling Our Future An Introduction to Sustainable Energy," Cambridge University Press, United State of America, 2007.

[8] R. J. Campbell, "Increasing the Efficiency of Existing Coal-Fired Power Plants," Congressional Research Service 7-5700 www.crs.gov R43343, USA, 2013.

[9] http://www.c2es.org/technology/overview/electricity. [Online].

[10] F. C.B. Alcock DSc, Thermochemical Processes, Principles and Models, Butterworth Heinemann: OXFORD AUCKLAND BOSTON JOHANNESBURG MELBOURNE NEWDELHI, 2001, p. 43.

[11] J. a. S. Stulzt, Steam, its generation and use, Barberton Ohio USA: The Babcock \& Wilcox Company a McDermott company, 2005, p. 422.

[12] H. P.Bloch, Steam Turbines, Design, Applications, and Rerating, New York, Chicago,San Fransisco,Lisbon,London,Madrid,Mexico City,Milan,New Dehli,San Juan Seoul,Singapur,Sidney, Toronto: MC.Grawhill, 2009, pp. 261-268.

[13] Kehlhofer, Combined-Cycle Gas\&Steam Turbine Power Plants, Tulsa, Oklahoma: Pennwell, 1997, pp. 197-200.

[14] R. Kehlhofer, Combined-Cycle Gas\&Steam Turbine Power Plants, Tulsa, Oklahoma: Pennwell, 1997, pp. 
197-200.

[15] Recognized as an American National Standard (ANSI)IEEE Std 666-1991, "Design Guide for Electric Power Service Systems for Generating Stations.)," American National Standards Institute, USA, 1991.

[16] D. E. Winterbone, Advanced Thermodynamics for Engineers, LONDON SYDNEY AUCKLAND Copublished in North, Central and South America by John Wiley \& Sons, he., New York Toronto: Arnold.A member of the Hodder Headline Group, 1997.

[17] Adnal, "Analisis efisiensi termal PLTU Ni Tanasa dengan memakai bahan bakar rendah kalori berkapasitas 2*10 MW," Pendidikan Fisika PLTE FKIP UHO, Kendari, 2019.

[18] B. Winardi, "Analisis Konsumsi Bahan bakar pada pembangkit listrik Tenaga Uap (Studi kasus di PT Indonesia Power Semarang," in Seminar Nasional Electrical and informatics and IT'S Educations 2009, Semarang, 2009. 